\title{
UNDERSTANDING E-BUSINESS COMPETENCIES IN SMES
}

a conceptual and operational approach

\author{
TOM R. EIKEBROKK and DAG H. OLSEN \\ Department of Information systems, Agder University College, Norway
}

\begin{abstract}
This paper reports on an ongoing project that aims to assist SMEs in the strategic use of e-business technology. We present the first stage of this project, where the goal is to identify critical types of competence that can enable or inhibit the successful use of e-business technologies. We start by describing the conceptual model of competencies and their relations to ebusiness success. Secondly, we describe the operationalization of this model into measures that are the basis for the subsequent survey used to identify critical types of competence related to e-business success for SMEs.
\end{abstract}

\section{INTRODUCTION}

One of the major characteristics of today's economy is the growth of ebusiness defined as business conducted over the Internet. All over the world both established companies and new ventures create new online businesses based on Internet technologies, which are therefore often referred to as ebusiness technologies, e-commerce solutions, etc. It is generally believed that e-business has the potential of increasing efficiency and effectiveness and hence generate substantial new value.

Research within the field of information systems (IS) economics show that the business value from IT investments in general is positive and highest in companies that not only invest in technology but also in organizational measures including training programs to leverage ITs potential (Brynjolfsson and Hitt, 1998). Most studies of the effects of IT-investments are done in the context of large firms, usually Fortune 500 companies, and there are very few studies of IT-value in smaller companies. In a recent study based on 441

The original version of this chapter was revised: The copyright line was incorrect. This has been corrected. The Erratum to this chapter is available at DOI: 10.1007/978-0-387-35692-1_36 
small and medium-sized enterprises (SMEs) in Spain Dans (2001) found that IT-investments also gave a significant and positive business value in SMEs.

Moreover, in a recent study Amit and Zott (2001) argue that amongst ITinvestments in general Internet technologies have the highest potential for value-creation through linking companies, its suppliers and customers in new and innovative ways. Amit and Zott further argue that this value potential of e-business is poorly understood both theoretically and in practice. In a European survey among Internet experts and online traders it was found that most companies did not consider e-business as a priority (Forrester Research, 1999). Among the major obstacles were lack of trained staff and co-ordination between internal departments. Knowledge and competence are increasingly emphasized by businesses in general as the most important competitive factor. In particular, small and medium sized enterprises suffer from resource poverty. In a similar European survey among SME managers it was found that the main obstacles to increased competence were high costs of courses, problems of internal organization of the attendance to the courses, bad quality of the training supply as well as difficulties in identifying training needs $(E / 1224,1997)$. With the knowledge of key competencies, SMEs may spend their limited resources on factors that contribute the most to business value.

The purpose of this paper is to contribute to the theoretical and practical understanding of the nature and role of competence in utilizing e-business technology for the benefit of the business. In exploring this we are particularly concerned with the small- and medium sized companies. To do this, we begin with a review of the literature describing the company value of e-business, and the nature and importance of competencies needed to successfully utilize information technology including e-business solutions. Based on this review, we develop a conceptual model of e-business competencies and their relations to e-business value. In the empirical part of the paper we test the relevance of this model for SMEs through interviews with selected managers. These interviews also guide the operationalization of the model into a survey instrument. The final section of the paper presents a summary and conclusion of the theoretical and empirical work in the paper.

\section{THEORY}

There is an increased focus on individual achievement and productivity in the workplace (Stewart, 1997). In today's competitive environment, maximizing the potential of information technology in general and Internet technology in particular presumes that the technology is used well and not 
only adopted and used. Competence is a primary issue, as it enables employees to transform ideas into business value (Soh \& Markus, 1995; Kanter, 1997), and as it leads to higher productivity (Higginbotham, 1997; Little, 1997).

Only a few studies have examined the relationship between information technology competence in general and business value. Also, the user competence construct is largely absent from prominent technology acceptance and fit models, poorly conceptualized, and inconsistently measured (Marcolin et al., 2000). Recent works show increased academic interest in this phenomenon.

Amit and Zott (2001) have explored the theoretical foundations for value creation in e-business in a recent study. Their review suggests that no single theory available in the entrepreneurship or strategic management literature today can fully explain the value creation potential of e-business. Rather, they argue that an integration of theoretical perspectives on value creation is necessary. Their proposed model is based on the concept of a business model, which describes how one or several companies (e.g. a company and its suppliers and customers) in co-operation can exploit business opportunities through the design, structure and governance of transaction content. With this as the level of analysis, they describe the potential of value creation in e-business in four interrelated dimensions, which are efficiency, complementarities, lock-in, and novelty. Efficiency relates to potential of reducing transaction costs as a result of utilizing e-commerce technologies. Complementarities describe the value potential of companies that cooperate in an e-business strategy and combine their products and services, technologies and activities. This combination can create value to customers as a result of reduced costs related to finding and ordering products and services, and to business partners as a result of utilizing interconnectivity of markets and possibilities of process integration. The third dimension, lock-in, describes the value potential of e-business as a result of switching costs where customers are motivated to repeat their transactions, and where business partners extend their relationships and also improve their current associations. As the last dimension in Amit and Zott's model, novelty describes how e-businesses can create value through innovations in the way business is conducted. Examples of such innovations are new ways of structuring transactions like web-based auctions and reverse markets. In the latter form potential buyers indicate needs and preferred prices to sellers. These examples show that e-business combines previously unconnected parties by utilizing new transaction technologies and by creating new markets. 


\section{$2.1 \quad$ IT Competence}

According to Marcolin et al. (2000) and Basselier et al. (2001) the proliferation of approaches to the concept of competence has hindered the creation of a cumulative body of knowledge. Research has been conducted from a variety of approaches and areas of research, including psychology, human resource management, management, education and information systems. Partly, this confusion in the understanding of competence results from the interchangeable use of competence and performance, which confuses the understanding of process and outcome. Problems related to understanding and measuring competencies have caused many researchers to use performance as a proxy. In this study we will view an organization's access to competencies as a necessary but not sufficient factor to the successful implementation of strategies involving new technologies. We will primarily base our discussion and inclusion of potentially important areas of competence on studies within the IS field that include some form of outcome in either general or specific terms. Furthermore, since several studies point to the importance of the business manager in achieving successful implementation of strategies and technologies (e.g. Luftman et al. 1999; Papke-Shields and Malhotra 2001), we will also include studies which focuses on the business manager. In the interviews and in the survey we will also focus on business managers and hence assume that information from these will give a representative reflection of both relevant and critical types of competence in SMEs. Since the literature on e-business is more influenced by studies of bigger companies, we base our approach on the assumption that we can gain more understanding of e-business in SMEs by applying theories based on studies of businesses in general and adjusting them to the SME context.

\subsubsection{Definitions and types of competence}

In this emergent field of IS research there is yet little general agreement on how competencies should be defined and measured. There are different views concerning which elements competence consist of, and at what level of analysis these could be observed. In the IS field two streams of research considering the nature and importance of competence can be identified. Firstly, one stream concerns competencies needed at the company level of analysis and is influenced by similar studies reported in the management literature (e.g. Prahalad and Hamel, 1990). In particular, this stream is heavily influenced by the resource-based view of the firm (e.g. Barney, 1991) where competencies are regarded as resources defined as fundamental drivers of superior company performance. In addition, a distinction is made 
between resources and capabilities, where capabilities reflect the company's ability to combine resources in ways that stimulate performance. In general the goal of this research is to identify types of capabilities that are core in the sense that they can create a relative advantage to the company in it's effort of taking advantage of technology in relation to business needs. A persistent issue in this research stream has been to identify which types of competence in terms of resources and capabilities that are core and non-core to the business.

The other stream concerns the competencies at the individual level. This perspective holds that competence at the individual level is required for the creation of competence at the organizational level, or focuses simply on the competence requirements that individuals will be subject to (Lee and Trauth, 1995; Basselier et al., 2000). There is incomplete research at the individual level as is also reported in organizational research (Nordhaug, 1998).

Table 1 shows the level of analysis and definition of competence of the most significant recent contributions to the conceptualization of IS competence.

\begin{tabular}{|c|c|c|}
\hline & Level of analysis & Definition of competence \\
\hline Van der Heijden (2000) & $\begin{array}{l}\text { Organizational level and IT } \\
\text { management }\end{array}$ & $\begin{array}{l}\text { IT core capabilities: } \\
\text { organization-specific routines, } \\
\text { processes, skills and resources }\end{array}$ \\
\hline $\begin{array}{l}\text { Feeny and Willcocks } \\
\text { (1998) }\end{array}$ & $\begin{array}{l}\text { Organizational level and IT } \\
\text { management }\end{array}$ & $\begin{array}{l}\text { IS core capabilities: } \\
\text { organization-specific routines, } \\
\text { processes, skills and resources }\end{array}$ \\
\hline $\begin{array}{l}\text { Sambamurthy and Zmud } \\
\text { (1994) }\end{array}$ & $\begin{array}{l}\text { Organizational level and IT } \\
\text { management }\end{array}$ & $\begin{array}{l}\text { Capabilities, skills and tacit } \\
\text { know-how }\end{array}$ \\
\hline $\begin{array}{l}\text { Bharadwaj, Sambamurthy } \\
\text { and } Z \text { mud (2000) }\end{array}$ & Organizational level & Critical IT capabilities \\
\hline Basselier et al. (2001) & $\begin{array}{l}\text { Individual level and business } \\
\text { managers }\end{array}$ & $\begin{array}{l}\text { IT related explicit and tacit } \\
\text { knowledge }\end{array}$ \\
\hline Lee and Trauth (1995) & $\begin{array}{l}\text { Individual level and IS } \\
\text { professionals }\end{array}$ & Critical knowledge and skills \\
\hline
\end{tabular}

Table 1. Approaches to the study of IS competence

IT-competence in business managers can be defined as "the set of ITrelated knowledge and experience that a business manager develops over time which enables him/her to contribute effectively to the deployment of IT in the organization" (Basselier et al., 2001). Basselier et al. identifies five areas of knowledge that a manager should possess: technology, applications, system development, management of IT and access to IT knowledge. In addition to this knowledge, business managers' level of competence is increased by experience both at the project level and in the management of 
IT. At the management of IT level, such activities are creation of IT vision, strategies and policies, budget, priorities of development, and communication mechanisms between IT and business people.

This area is perhaps most examined in the IT and related literature. In a literature review, Marcolin et al. (2000) observed three factors differentiating the measures of competence: Conceptualizations of competence, measurement methods and knowledge domains. The different conceptualizations identified by Marcolin et al. are associated with three outcomes from learning: cognitive outcomes, skill-based outcomes and affective outcomes (Kraiger, Ford and Salas, 1993). These outcomes represent different conceptualizations of competence, and can be used to understand differences in the effectiveness of the employment of technology (Marcolin et al., 2000).

What are less studied are the non-IT aspects of technology. It is generally accepted that such meta-skills as communication, social and leadership skills are necessary for successful IT professionals. To what extent such competence is needed in different organizational roles is a rich potential area of study. A growing body of research investigating the importance of alignment between business and technology has documented that having competencies in business strategy and IS strategies per se is not enough to successfully take advantage of new technologies (e.g. Luftman et al., 1999). Alignment which is defined as applying IT in an appropriate and timely way, in harmony with business strategies, goals and needs (King, 1995; Henderson and Venkatraman, 1993) can be viewed as one type of competence involving such meta-skills not related to technology it self. Thus, alignment as a competence involves combining and using the available competencies inside or outside of the organization in a way that realizes the strategic potential of new technologies in the company's business domain. Henderson \& Venkatraman (1993) describes the process of alignment as a managerial role where the task primarily is to create a strategic fit between the external position of the organization in the competitive product-market arena and the internal design of an appropriate administrative structure that supports its execution. In achieving this alignment the organization must combine its available competencies on strategy and strategy formulation with competencies on technologies and internal operations. Alone, sophisticated technologies have no value without the competence that makes the organization capable of organizing its processes in a way that realizes the potential of the new technology and hence differentiate the organization from its competitors.

Knowing how to stimulate the active use and combination of relevant competencies is therefore important, but not straightforward. In an extensive longitudinal study of more than 500 companies in 15 industries, Luftman et 
al. (1999) identified factors that enables or hinders the successful alignment between business and IT strategies. Based on interviews with both business and IT managers, the results showed that one of the most important enablers of alignment was a business manager that recognized the potential value of IT, defined and communicated visions and strategies which included IT, as well as actively sponsored IT projects.

In a study of the manufacturing executive's role on business performance through strategic alignment, Papke-Shields and Malhotra (2001) found that both active involvement and influence from the business executive were important determinants of alignment which again had a significant influence on business performance.

\subsubsection{Theoretical synthesis}

There is general agreement in the literature that the successful use of IT assumes organizational and individual capabilities. There are different approaches to conceptualizing this phenomenon in the literature. Many terms are used in the IS field to describe organizations' capabilities. Some researchers describe this with terms like core capability (Feeny and Willcocks, 1998; Amit and Schoemaker, 1993; Penrose, 1959; Teece et al. 1997). Others use core competence (Sambamurthy and Zmud, 1994), explicit and tacit knowledge (Basselier et al., 2000) or distinguishes between cognitive, skill-based and affective dimensions of competence (Marcolin et al., 2000; Kraiger et al., 1993). We base our conceptualization on the integrative terms of Sambamurthy and Zmud (1994) that integrate organizational level concepts with individual level concepts. They view these dimensions as organizational competencies that exist of organizational capabilities (e.g. supportive organizational culture), individual skills (e.g. IT personnel skill base) and tacit know-how (e.g. individual experience in reorganization of work processes).

The literature on competence is so far more influenced by studies of ITinvestments related to traditional business rather than e-business that highlights new and technology based interactions between companies. As a result, several models do not include competence on whether activities should be sourced within the company or within the e-business network. Such competence in sourcing and also in alignment can be viewed as secondary types of competence, where sourcing relates to obtaining and alignment relates to combining and use primary types of competence.

Most of the literature on competence is based on studies of relatively large companies. We need to adjust these models to fit smaller companies. It is very likely that smaller companies have fewer resources and as a result experience constraints to strategies and actions relevant to bigger companies. 
The literature is not clear as to what these differences are. It is therefore necessary to test the conceptual model for its relevance to SMEs, which will be done in the next section.

\section{THE CONCEPTUAL MODEL}

The next step was to create a competence model that would work in our context. We performed a process of contrasting the dimensions of competence from the literature review in order to identify a common framework. The items of each dimension were clustered into appropriate dimensions for our study. We discussed the clusters and the items in terms of the significance for SMEs and e-business. Discussion with colleagues and open-ended interviews with SME leaders were used in this process. This process resulted in a model with six dimensions of competence as shown in figure 1. Our dimensions are elaborated below. Table 2 shows how our dimensions of competence relate to the dimensions in the literature review. Appendix 1 shows how our competence dimensions relate to the items of the most significant sources.

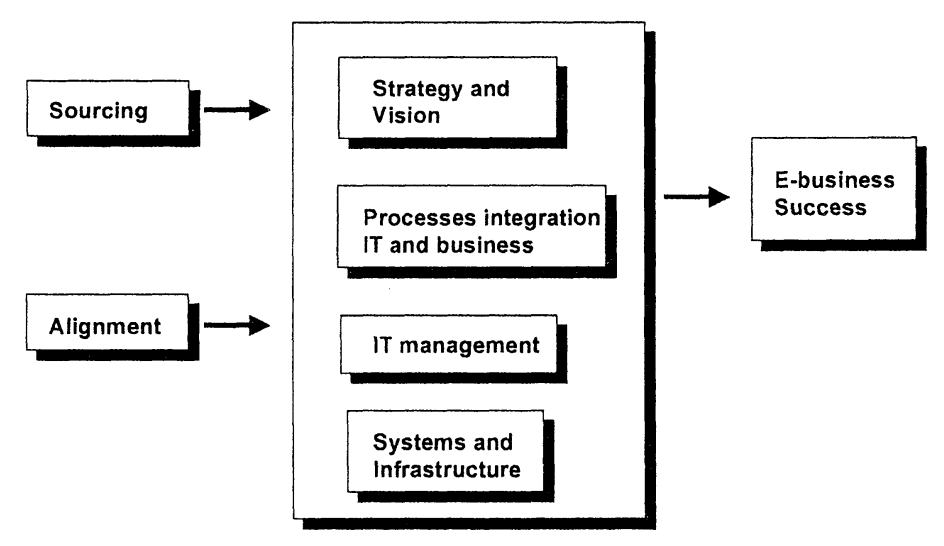

Figure 1. The conceptual model 
Bharadwaj, Sambamurthy and $\begin{array}{ccccc}\begin{array}{c}\text { Strategy } \\ \text { and vision }\end{array} & \begin{array}{c}\text { IT-Business } \\ \text { process } \\ \text { integration }\end{array} & \text { management } & \text { Systems and } & \text { Sourcing and } \\ \text { Infrastructure } & \text { Alignment }\end{array}$ Zmud, 2000

IT business partnerships

External IT linkages

Business IT strategic thinking

IT business process integration

IT management

IT Infrastructure

Basselier, Reich and Benbasat, 2001

Explicit IT Knowledge

Technology

Applications

Systems Development

Management of IT

Access to IT knowledge

Tacit IT Knowledge

Experience

Cognition

Feeny and Willcoks, 1998, van der Heijden, 2000

Business IT Strategic

Thinking(BIS)

IT management(ITM)

Business Systems

Thinking(BST)

Relationship Building(RB)

Architecture Planning(AP)

Making Technology

Work(MTW)

Informed Buying(IB)

Contract Facilitation(CF)

Contract Monitoring(CM)

Vendor Development(VD)

Sambamurthy and Zmud,1994

Business Development

External Networks

Line Technology Leadership

Process Adaptiveness

IT Planning

IT Infrastructure

Data Center Utility

Lee and Trauth, 1995

Technical Specialties

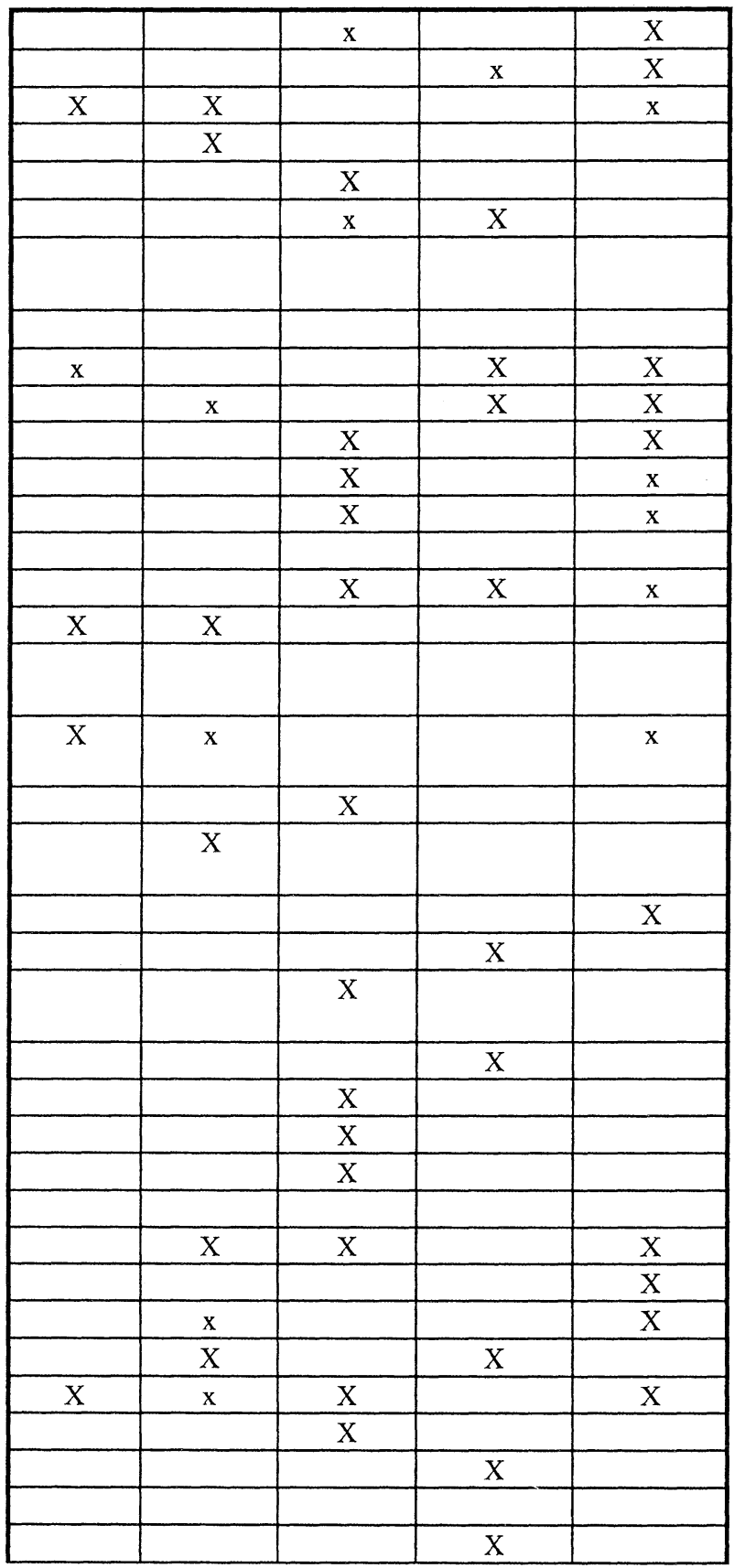




\begin{tabular}{|c|c|c|c|}
\hline \multicolumn{4}{|l|}{$\mathrm{K}_{\mathrm{I}}$} \\
\hline $\begin{array}{l}\text { Technology Management } \\
\text { Knowledge }\end{array}$ & & $\mathrm{X}$ & \\
\hline $\begin{array}{l}\text { Business Functional } \\
\text { Knowledge }\end{array}$ & $X$ & & $X$ \\
\hline $\begin{array}{l}\text { Interpersonal and Management } \\
\text { Skills }\end{array}$ & & $X$ & X \\
\hline
\end{tabular}

Table 2. The relation between the conceptual model and the major sources.

\subsection{Strategy and Vision}

This dimension describes the company's ability to envision the strategic potential of new e-business or e-commerce technology in its marketplace. The dimension both involves understanding the concept of e-business and how related new technology for e-commerce can represent threats and opportunities to the company. Included here is also the ability to understand and use strategic planning methods needed to develop an e-business strategy.

Strategy and vision as a variable will reflect the maturity of the enterprise in both understanding the e-business domain and what it means in terms of new possibilities and threats in the business domain. The variable will also reflect the organizational capability to develop plans, which describes how e-business will be put into action.

The importance of this variable was supported by our interviews with eight SME managers and two consultants specializing in IT and business issues in SMEs. The most important issues, according to these managers and consultants, were the visions and strategies related to the utilization of ebusiness and the implications of e-business on the work processes both within the SMEs and their business partners.

\subsection{Sourcing and Alignment}

Sourcing and alignment describes activities related to the company's ability to involve and take advantage of competencies inside or outside of the company in order to develop and implement strategies related to ebusiness. The importance of these variables is well documented in the literature. Sourcing refers to whether competencies will be build up internally or accessed from external sources, either through insourcing of competencies or outsourcing of activities where competencies are needed. When competencies are not sufficiently represented internally, the company must decide what strategy it will utilize to close this gap. Identified competencies could be build up internally through education programs or 
through recruitment of new personnel. Alternatively, the activity where competencies are needed could also be partly or totally outsourced to partners in the business network. The company could also implement some combination of these strategies. Sourcing of competence describes the process of gaining access to competencies inside or outside of the company.

Having access to sources of competence per se both inside or outside of the company is not enough for the successful use of competence. Work processes whether they are located inside or outside of the company, can be intertwined and dependent on each other. In the effort of designing new processes, or improving existing processes, the company must make competencies work together in order to realize the potential of information technology. The concept of alignment describes both the process of how different competencies represented in different sources are brought together and put into action, and the outcome of this process as a resulting level of alignment. Previous work on the alignment between business and IT shows that departments, business and IT experts must be brought together and involved in the effort of combining IT possibilities with business needs and opportunities. Relationships must be built between IT professionals and business unit managers. Research on both alignment and sourcing has documented that both the choices of alignment strategy and sourcing strategy are related to company performance.

In our model, sourcing and alignment represent meta or secondary competence that involve using and combining the primary types of ebusiness competence that the company possesses. The rationale behind this variable is that primary types of e-business competence are necessary but not sufficient for the successful use of these competencies. The company must also have secondary types of competence in terms of the ability to combine competencies in a relevant way in support of their visions and strategies.

\subsection{IT-Business Process Integration}

This variable describes the organization's capability of envisioning and implementing work processes made possible by new technologies. New business or IT work processes can be designed or old processes can be restructured in order to leverage the opportunities of new technology. Independent of which strategy is chosen, the company must have the necessary capability to identify and implement changes in business processes in order to increase process efficiency to the relevant level according to the technology chosen.

The notion that one must organize in order to leverage the potential of new technology has been wide spread in the IS literature. Empirical studies in the area of IS economics have also documented that productivity gains in 
Fortune 500 companies from utilizing new technologies are higher in companies that organize themselves in ways that leverage the potential of the new technology (e.g. Brynjolfsson and Hitt, 1998). In a European study of 441 Spanish SMEs, Dans (2001) found a similar correlation between ITinvestments and productivity for SMEs that can partly be attributed to organizational redesign. This means that companies must look for new and powerful ways of both organizing and managing their work processes. To do this, competencies are both needed in developing the new business model and in the subsequent implementation of this model in the organization. We describe these types of competence as IT-business process integration.

\subsection{IT Management}

IT management is activities related to the management of the IT function. This is activities such as IS planning and design, IS application delivery, IT project management, and planning for controls and standards (Bharadwaj et al., 2000; DeLone, 1988). Research on SMEs shows that these companies seldom have a defined IT budget or an explicit IT plan or strategy, and investments in technology are often driven by the owner, rather by any formal cost-benefit or strategic analysis (Ballantine et al., 1998; Dans, 2001). This was also supported in our interviews with eight managers from SMEs and two consultants working with IT- and business issues in SMEs, where IT management in general and the specific activities like formal and specific IT plans mentioned above, were perceived as less important in relation to ebusiness. As a result of this we do not define specific activities in IT management, but keep this at a more general level.

\subsection{Systems and Infrastructure}

This dimension refers to the foundation for enterprise applications and services, and is comprised of data, network, and processing architectures. Systems and infrastructure influence the reach and range of business opportunities available to firms in applying IT in their business strategies.

Successful use of e-business technologies involves both finding the right technology with a strategic potential to implement and having a technological and managerial infrastructure that can support it. This involves competence on available e-business solutions as well as on the importance of having or creating internal structures that can utilize the new solutions.

SMEs generally are dependent on a small number of customers to whom they sell a limited number of products. SMEs will thus often be heavily influenced by the e-business strategy of the dominant actor in the value chain, and be forced to conform to their solutions and technology (Ballantine 
et al., 1998), and thus the competence requirements defined by this. We have therefore reduced the level of detail in the specific competencies related to systems and infrastructure, and to a more general level. Our choice here was also supported by the interviews with SME managers and consultants who perceived competencies related to systems and infrastructure as of much less importance that competencies in vision and strategy along with competencies in integrating work process between business and IT. Furthermore, the interviews also revealed that several SMEs had experienced lack of control and autonomy regarding IT decisions that involved an important customer or business partner.

\subsection{E-business Success}

We define e-business success in line with Amit and Zott (2001) who describe the potential of value creation in e-business in four interrelated dimensions, which are efficiency, complementarities, lock-in, and novelty. Efficiency relates to possible reduction in transaction costs, whereas complementarities describe the value potential from combining products and services, technologies and activities with an e-business partner. The third dimension, lock-in, describes the potential value in creating switching costs from arrangements that motivate customers and business partners to repeat and improve transactions and relationships. The last dimension, novelty, describes value as a result of innovations in the way business is conducted (e.g. web based auctions, etc.).

\section{DEVELOPMENT OF SURVEY INSTRUMENT}

The conceptual model was developed in order to establish the dimensions of the survey instrument. This survey will later be used in identifying types of competence that are critical in realizing e-business value in SMEs in five European countries. Figure 2 depicts the phases in the development of the survey instrument. The initial conceptual model was developed on the basis of the literature review. The integration and relation of the major contributing articles to our initial conceptual model is organized in a matrix in appendix 1. The initial model was discussed with colleagues in a research seminar. This spurred some minor adjustments and a further literature review, which led to the final conceptual model. This served as input to the development of an operational model with the initial list of survey indicators.

We then conducted open-ended interviews with eight executives of Norwegian SMEs and two related consultants, as an additional reality check 
of this model, and as a guide to the further elaboration of our dimensions and specific indicators. Since small businesses most likely have different characteristics from large companies, the purpose of the interviews was also to include factors relevant to the context of small businesses. These interviews started open-ended to obtain possible fundamental changes or additions to our conceptual model. We then gradually narrowed the focus in the interviews to elicit more specific information. The outcome of this process led to an improved final conceptual model, which is assumed to be relevant for SMEs.

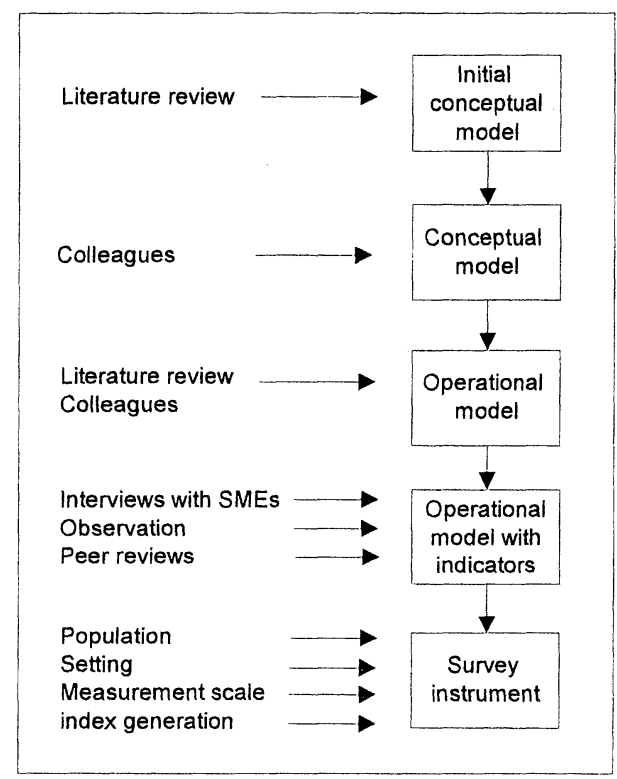

Figure 2. Phases in the development of a conceptual model and survey instrument

The list of indicators was turned into a preliminary list of survey questions. This list was subject to further refinement through pre-testing in a new sample of SMEs. The national partners of the ANTRA project subsequently translated the survey into Norwegian, Finnish, and Spanish, and surveys are currently being carried out in 3 industries in each partner country.

\section{RESULTS AND DISCUSSION}

Our review of the literature suggests that e-business competence can be conceptualized into the six dimensions of our conceptual model. The 
relationships between these dimensions and the major contributing articles are shown in the matrix in appendix 1 . The review of the literature and the interviews with SMEs indicate that the general conceptual model is relevant also to SMEs. The survey instrument is presented in appendix 2 .

The interviews also indicated that some types of competence are perceived by SMEs as more relevant than others in the context of e-business. SME managers and consultants considered competencies in strategy and vision, IT-business process integration, and sourcing as most important. Competencies in IT management, systems and infrastructure and alignment were considered relevant but less prioritized in relation to the other types of competence. Competence in sourcing was described as particularly important since this is strongly related to the importance of the local network to SMEs in general. Both managers and consultants described the local network of business partners as an important relationship since it is characterized by higher trust and less costs than partners outside of the local area. As a result of this, SMEs rest heavily on local partners and associates when issues of importance to their business are discussed.

The interviews also pointed to the influence of significantly bigger business partners. SMEs generally have small market shares. They are typically dependent on a small number of customers to whom they sell a limited number of products (Ballantine et al., 1998). SMEs will therefore most likely be influenced by the e-business strategy of the dominant actor in the value chain. In this case, SMEs will experience less autonomy in both choosing the appropriate technology and the related competencies. We have some support for this argument in our interviews with SMEs, and it should be investigated further. We have included control variables in the survey instrument to address this situation.

In this research we assume that developing and implementing an ebusiness strategy is an ongoing process in most SMEs. One interview, however, revealed that e-business was not perceived as a new issue. This SME had already and long ago implemented electronic communication and transactions with its major business partners. The technology used was not originally based on Internet but gradually this technology had been replaced by Internet solutions. This replacement was regarded as a pure technical issue and was now almost completed. As a result of this, the manager did not perceive e-business competence as relevant because the process of utilizing information technology to assist business transactions was close to its end. This interview show that some companies might perceive the issue of competence as irrelevant since the process of implementing e-business is ended. To control for this situation we have included items to measure this process in the survey instrument. 
Our interviews and some studies in the reviewed literature suggest that SMEs experience a different reality than large companies. Some studies suggest that resources in general are much scarcer in SMEs, and managers or other personnel fill many roles at the same time. The use of formal planning methods and strategic plans per se is often limited. It is not clear in the literature how and when size of a company leads to specialization and formal structures. To more fully understand the differences between big and small companies we need more research into this issue. More research will increase our knowledge of what and when important conditions are in place and to what extent they can stimulate business development in general and ebusiness success in particular.

\section{ACKNOWLEDGEMENTS}

This paper benefited from work conducted under the ANTRA project that is partly financed by the EU Commision and the Leonardo da Vinci program.

\section{REFERENCES}

Amit, R. \& P. Schoemaker (1993), 'Strategic assets and organizational rent', Strategic Management Journal, 14(1), 33-46.

Amit, R. \& C. Zott (2001), 'Value creation in e-business', Strategic Management Journal, 22, 493-520.

Barney, J.B. (1991), 'Firm resources and sustained competitive advantage', Journal of Management, 17, 99-120.

Ballantine, J., M. Levy \& P. Powell (1998), 'Evaluating information systems in small and medium enterprises', European Journal of Information Systems, 7, 241-251.

Basselier, G., B.H. Reich \& I. Benbasat (2001), 'Information technology competence of business managers: a definition and research model', Journal of Management Information Systems, 17(4), 159-182.

Bharadwaj, A.S., V. Sambamurthy \& R.W. Zmud (2000), 'IT capabilities: theoretical perspectives and empirical operalization', in 'Proceedings of the 21 th International Conference on Information Systems', Brisbane, Australia, 378-385.

Brynjolfsson, E. \& L.M. Hitt (1998), 'Beyond the productivity paradox: computers are the catalyst for bigger changes', Communications of the ACM 41(8), 49-55.

Dans, E. (2001), 'IT investment in small and medium enterprises: paradoxically productive?', The Electronic Journal of Information Systems Evaluation, 4(1), March.

DeLone, W.H. (1988), 'Determinants of success for computer usage in small business', MIS Quarterly, 12(1), 51-61.

Feeny, D.E. \& L.P. Willcocks (1998), 'Core IS capabilities for exploiting information technology', Sloan Management Review, Spring, 9-21.

Forrester Research, (1999), in 'Connectis, Europe's E-business Magazine' 1(1),

E/1224, (1997), 'Training processes in SMEs: practices, problems and requirements'. 
Henderson, J.C. \& N. Venkatraman (1993), 'Strategic alignment: leveraging information technology for transforming organizations', IBM Systems Journal, 32(1), 4-16.

Higginbotham, J.S. (1997), 'The satisfaction equation', $R \& D$, 39(10).

Kanter, R.M. (1997), 'The frontiers of management', Boston, Mass., Harvard Business School Press.

King, J. (1995), 'Re-engineering focus slips', Computerworld, March 13.

Kraiger, K., K. Ford, \& E. Salas (1993), 'Application of cognitive, skill based and affective theories of learning outcomes to new methods of training evaluation', Journal of Applied Psychology 78(2), 311-328.

Lee, D.M.S. \& E.M. Trauth (1995), 'Critical skills and knowledge requirements of IS professionals: a joint academic/industry investigation'. MIS Quarterly, 19(3), 313-340.

Little, B. (1997), 'The have-nots of the new technology', The Globe and Mail Monday. Toronto, Canada.

Luftman, J.N., R. Papp \& T. Brier (1999), 'Enablers and inhibitors of business IT alignment'. Communications of the Association for Information Systems, 1 (11).

Marcolin, B.L., D.R. Compeau, M.C. Munro \& S.L. Huff (2000), 'Assessing user competence: conceptualization and measurement'. Information Systems Research, 11(1), $37-60$

Nordhaug, O. (1998), 'Competence specificities in organizations', International Studies of Management and Organization, 28(1), 8-29.

Penrose, E.T. (1959), The theory of the growth of the firm, Oxford, Basil Blackwell.

Papke-Shields, K.E. \& M.K. Malhotra (2001), 'Assessing the impact of the manufacturing executive's role on business performance through strategic alignment'. Journal of Operations Management, 19 (1).

Pralahad, C.K. \& G. Hamel, (1990), 'The core competence of the corporation'. Harvard Business Review, May-June, 79-91.

Sambamurthy, V. \& R.W. Zmud, (1994), 'IT management competency assessment: a tool for creating business value through IT', Financial Executives Research Foundation, Morristown, New Jersey.

SSB: 'Informasjonssamfunnet', Kvartalsrapport 1/2000. Norwegian Bureau of Statistics.

Soh C. \& M.L. Markus (1995), How IT creates business value: a process theory synthesis, in 'Proceedings of the Sixteenth Conference on Information Systems', Amsterdam, The Netherlands, December, 29-41.

Stewart, T., 1997: 'Intellectual capital', Doubleday Press, New York.

Teece, D.J., G. Pisano \& A. Shuen, (1997), 'Dynamic capabilities and strategic management', Strategic Management Journal, 18(7), 509-533.

Van der Heijden, H. (2000), Measuring IT core capabilities for electronic commerce: results from a confirmatory analysis, in 'Proceedings of the 21 th International Conference on Information Systems', Brisbane, Australia, 152-163. 
Appendix 1. The relation between the conceptual model and the major sources.

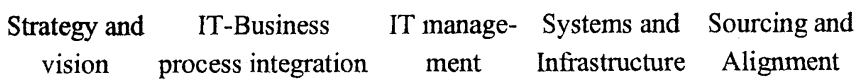

Bharadwaj,

Sambamurthy and

Zmud, 2000

IT business

partnerships

\begin{tabular}{|c|c|c|c|c|c|}
\hline \\
\hline IBP1 & & & & & $\mathrm{X}$ \\
\hline IBP2 & & & & & $\mathrm{X}$ \\
\hline IBP3 & & & & & $\mathrm{X}$ \\
\hline IBP4 & & & $\mathrm{x}$ & & $\mathrm{X}$ \\
\hline IBP5 & & & $\mathrm{x}$ & & $\mathrm{X}$ \\
\hline IBP6 & & & & & $\mathrm{X}$ \\
\hline External IT linkag & & & & & \\
\hline EIT1 & & & & $\mathrm{x}$ & $\mathrm{X}$ \\
\hline EIT2 & & & & $x$ & $\mathrm{X}$ \\
\hline EIT3 & & & & & $\mathrm{X}$ \\
\hline EIT4 & & & & & $\mathrm{X}$ \\
\hline $\begin{array}{l}\text { Business IT } \\
\text { strategic thinking }\end{array}$ & & & & & \\
\hline BIT1 & $\mathrm{X}$ & $\mathrm{X}$ & & & $\mathrm{x}$ \\
\hline BIT2 & $\mathrm{X}$ & $\mathrm{X}$ & & & $\mathrm{x}$ \\
\hline BIT3 & $\mathrm{X}$ & $\mathrm{X}$ & & & $\mathrm{x}$ \\
\hline BIT4 & $\mathrm{x}$ & $\mathrm{X}$ & $\mathrm{x}$ & & $\mathrm{x}$ \\
\hline BIT5 & $x$ & $\mathrm{X}$ & $x$ & & \\
\hline $\begin{array}{l}\text { IT business proces } \\
\text { integration }\end{array}$ & & & & & \\
\hline BPI1 & & $\mathrm{X}$ & & & \\
\hline BPI2 & & $\mathrm{X}$ & & & \\
\hline $\mathrm{BPI} 3$ & & $\mathrm{X}$ & & & \\
\hline IT management & & & & & \\
\hline ITM1 & & & $\mathrm{X}$ & & \\
\hline ITM2 & & & $\mathrm{X}$ & & \\
\hline ITM3 & & & $\mathrm{X}$ & & \\
\hline ITM4 & & & $\mathrm{X}$ & & \\
\hline ITM5 & & & $\mathrm{X}$ & & \\
\hline ITM6 & & & $\mathrm{X}$ & & \\
\hline ITM7 & & & $\mathrm{X}$ & & \\
\hline IT Infrastructure & & & & & \\
\hline INF1 & & & & $\mathrm{X}$ & \\
\hline
\end{tabular}




\begin{tabular}{|c|c|c|c|c|c|}
\hline INF2 & & & & $\mathrm{X}$ & \\
\hline INF3 & & & & $\mathrm{X}$ & \\
\hline INF4 & & & $\mathrm{x}$ & $\mathrm{X}$ & \\
\hline INF5 & & & & $\mathrm{X}$ & \\
\hline $\begin{array}{l}\text { Basselier, Reich and } \\
\text { Benbasat, } 2001\end{array}$ & & & & & \\
\hline $\begin{array}{l}\text { Explicit IT } \\
\text { Knowledge }\end{array}$ & & & & & \\
\hline Technology & & & & & \\
\hline ET1 & & & & $X$ & $\mathrm{X}$ \\
\hline ET2 & & & & $\mathrm{X}$ & $\mathrm{X}$ \\
\hline ET3 & $\mathrm{x}$ & & & $\mathrm{X}$ & $\mathrm{X}$ \\
\hline Applications & & & & & \\
\hline EA1 & & $x$ & & $\mathrm{X}$ & $\mathrm{X}$ \\
\hline EA2 & & & & $\mathrm{X}$ & $X$ \\
\hline $\begin{array}{l}\text { Systems } \\
\text { Development }\end{array}$ & & & & & \\
\hline ES1 & & & $\mathrm{X}$ & & $X$ \\
\hline ES2 & & & $\mathrm{X}$ & & $\mathrm{X}$ \\
\hline Management of IT & & & & & \\
\hline EM1 & & & $X$ & & $\mathrm{x}$ \\
\hline EM2 & & & $X$ & & $\mathrm{x}$ \\
\hline $\begin{array}{l}\text { Access to IT } \\
\text { knowledge }\end{array}$ & & & & & \\
\hline EK1 & & & $\mathrm{X}$ & & $\mathrm{x}$ \\
\hline EK2 & & & $\mathrm{X}$ & & \\
\hline Tacit IT Knowledge & & & & & \\
\hline Experience & & & & & \\
\hline TE1 & & & & $\mathrm{X}$ & \\
\hline TE2 & & & $\mathrm{X}$ & & $\mathrm{x}$ \\
\hline TE3 & & & $\mathrm{X}$ & & $\mathrm{x}$ \\
\hline Cognition & & & & & \\
\hline $\mathrm{TCl}$ & & $\mathrm{X}$ & & & \\
\hline TC2 & $\mathrm{X}$ & $\mathrm{X}$ & & & \\
\hline $\begin{array}{l}\text { Feeny and Willcoks, } \\
1998 \text {, van der Heijden, } \\
2000\end{array}$ & & & & & \\
\hline $\begin{array}{l}\text { Business IT } \\
\text { Strategic Thinking } \\
\text { BIS }\end{array}$ & $\mathrm{X}$ & $\mathrm{x}$ & & & $\mathrm{x}$ \\
\hline $\begin{array}{l}\text { IT management } \\
\text { ITM }\end{array}$ & & & $\mathrm{X}$ & & \\
\hline
\end{tabular}


Business Systems Thinking BST

Relationship

Building RB

Architecture

Planning AP

Making Technology

Work MTW

Informed Buying IB

Contract

Facilitation $\mathrm{CF}$

Contract

Monitoring CM

Vendor

Development VD

Sambamurthy and

Zmud,1994

Business

Development

$\mathrm{BD} 1$

$\mathrm{BD} 2$

$\mathrm{BD} 3$

BD4

BD5

BD6

BD7

BD8

BD9

External Networks

EN1

EN2

EN3

Line Technology

Leadership

LT1

LT2

Process

Adaptiveness

PA1

PA2

PA3

IT Planning

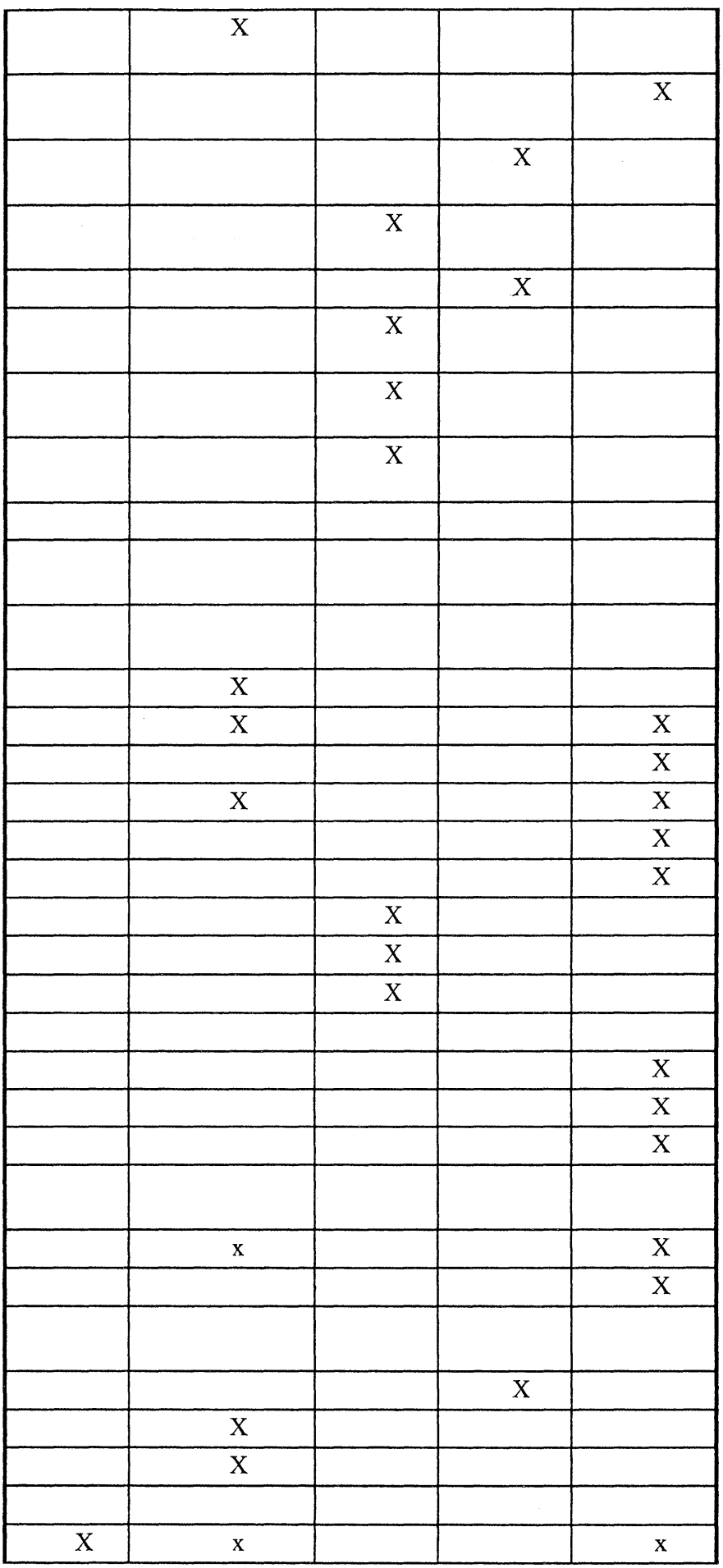




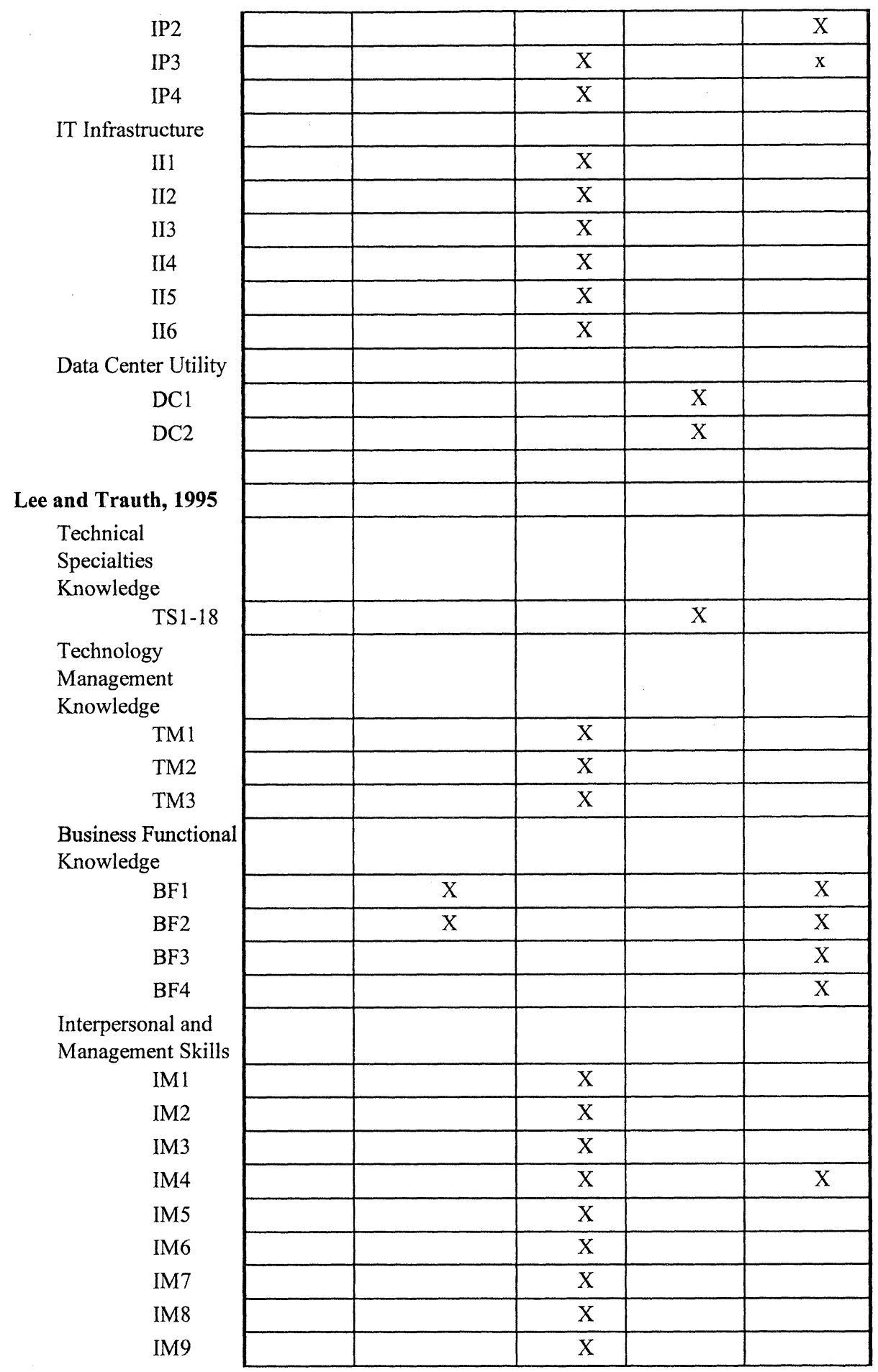


IM10

IM11

\begin{tabular}{|l|l|l|l|l|}
\hline & & $\mathrm{X}$ & & \\
\hline & & $\mathrm{X}$ & & $\mathrm{X}$ \\
\hline
\end{tabular}

Appendix 2. The Survey Instrument

\section{Country \\ O Finland O Norway \\ O Germany O Scotland \\ O Spain}

\section{INTRODUCTION TO RESPONDENT}

This interview is part of a project that investigates the use of e-commerce or e-business in small and medium-sized companies in Europe. In this interview you will be presented with questions about e-business, which can be defined as utilizing technologies for conducting business over the Internet. This implies all types of business interactions over the Internet with suppliers, customers and other business partners.

We ask you to answer as correct as possible based on the knowledge you have of your company. This survey is anonymous and we guarantee that it will not be possible to trace any of the answers back to you and your company.

First some introductory questions:

\section{BACKGROUND INFORMATION}

1. Approximately, how many employees are there in your company? employees

2. In what type of industry is your company?

\section{$O$ Tourism $O$ Transport $O$ Food \& Beverages}

3. Does your company use web pages, e-mail or e-commerce systems for business purposes?

O Yes O No

4. What types of e-business systems does your company use? (multiple responses possible)

$\mathrm{O}$ web pages whith information to individual customers about products or services

$\mathrm{O}$ web pages where individual customers can make orders

$\mathrm{O}$ web pages where companies can find information about products or services

O systems for electronic sales of products and services to other companies 
O EDI solutions on the Internet

O systems that enables your suppliers to see information about your demand or production O systems that integrates supply chains

$\mathrm{O}$ other

5. To what extent are IT activities in your company outsourced to external providers?
a very
a very

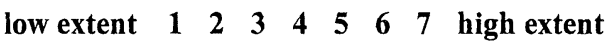

6. To what extent is your company informed about commercially available e-business systems?

a very a very

low extent $\begin{array}{llllllll}1 & 2 & 3 & 4 & 5 & 6 & 7 & \text { high extent }\end{array}$

7. To what extent is your company informed about providers of e-business related training?

a very a very

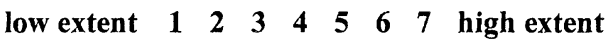

8. To what extent has your company implemented its e-business intentions?

a very a very

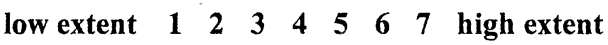

In the next section we would like you to assess your company's level of competence in various topics related to e-business. The questions are in the form of propositions. We ask you to give your evaluation of how accurately you feel that these propositions describe the situation in your company. If you find that any of the propositions are irrelevant, please indicate so by answering "not applicable". Please indicate how well you agree with the proposition by answering a number between 1: totally disagree and up to 7 : totally agree.

\section{STRATEGY AND VISION}

TOTALLY

DISAGREE
TOTALLY N/A

AGREE

$\begin{array}{lllllll}1 & 2 & 3 & 4 & 5 & 6 & 7\end{array}$ 
The concept of e-business

9. Our company has a high level of knowledge of how e-business technologies can be of value to our business

10. Our company has a high level of knowledge of how our main competitor(s) use IT to support similar business areas

11. In general, e-business is well understood by my company

1234567

Strategic planning

12. Our company has a high level of knowledge of strategic planning

1234567

13. Our company has a well developed set of strategic planning techniques

14. In general, strategic planning is well understood by our company

1234567

\section{SOURCING AND ALIGNMENT}

Sourcing competencies

15. Our company has a high level of knowledge on outsourcing of activities to other companies

16. Our company has a high level of knowledge on how to use competencies in our business partners

\section{Alignment competencies}

17. In my company business and IT managers very much agree on how IT contributes to business value

18. In my company there is effective exchange of 
19. In general, my company is good at using the competencies it already has

20. In general, my company is good at using competencies represented in our business partners

\section{IT-BUSINESS PROCESS INTEGRATION}

Competence in Process Integration

21. My company is actively working with the impact of e-business on its business processes

22. In general, my company is good at reorganizing work to utilize new information technology

\section{MANAGEMENT OF IT}

23. My company's IT resources are effectively managed

24. My company is good at achieving the anticipated benefits from IT investments

\section{SYSTEMS AND INFRASTRUCTURE}

25. The systems infrastructure is very flexible in relation to my company's future needs

26. The IT systems make it possible for my company to effectively cooperate electronically with 
business partners

In the last section we would like you to assess your company's experiences with the effects of its e-business efforts. We ask you to give your evaluation of what you feel has come out of your company's e-business efforts.

\section{E-BUSINESS SUCCESS}

\section{Efficiency}

Our e-business efforts have reduced costs by electronic order taking over the Internet

1234567

27. Our e-business efforts have made us able to deliver faster

1234567

28. Our e-business efforts have reduced costs in communication with suppliers and customers 1234567

\section{Complementarities}

29. As a result of our e-business efforts our products or services complement products or services from other suppliers

30. Our business efforts make it possible for other suppliers to complement our products or services

31. Our e-business efforts have made our supply chain strongly integrated to our partners' supply chains

\section{Lock-in}

Our e-business efforts make it more expensive for our customers or suppliers to replace us

32. Our e-business efforts have made our products and services more tailored to our customers' needs 


\section{Novelty}

33. Our e-business efforts have made our company a pioneer in utilizing e-commerce solutions

34. Our e-business efforts have made us cooperating with our customers or suppliers in new and innovative ways

\section{General}

35. In general, my company has experienced very positive effects from its e-business efforts

\section{OTHER/CONTROL}

\section{Leader vs. Follower}

There is a dominating customer or supplier who dictates our e-business efforts

36. Our company is good at implementing changes in its organization

37. Overall, my company has a high level of competence for utilizing e-business technology 